\title{
DEGRADATION OF SHORES IN THE URBAN AREA OF IRKUTSK CITY UNDER THE INFLUENCE OF MAN-MADE RESERVOIR
}

\author{
Kadetova A.V. ${ }^{1}$, Kozyreva E. A. ${ }^{1}$, and Rybchenko A. A. ${ }^{1}$ \\ I Institute of Earth Crust, Russian Academy of Sciences, Siberian Branch, 128 Lermontov street, \\ IrkutskE-mail: kadetova@crust.irk.ru; rybchenko@crust.irk.ru
}

\begin{abstract}
The paper deals with the problems of destruction of the shores of the Irkutsk manmade reservoir (Russia). The object of study is the dam-abut area of the reservoir. The reason of peculiar attention given to the shore degradation is that the areas in question are located within the urban territory; the degradation can entail considerable social and economical harm. The investigation of factors influencing the shore scouring was based on the available information on the wind and wave action and the level conditions in the reservoir, as well as the data on the properties and state of grounds in the studied area. The investigation revealed that the water level variations and the ground properties are the main factors responsible for the shore degradation and preventing of its attenuation.
\end{abstract}

Key words: abrasion, urban territory, man-made reservoir.

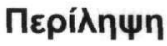

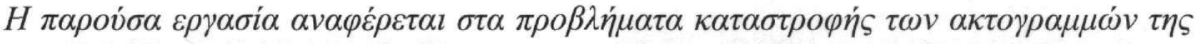

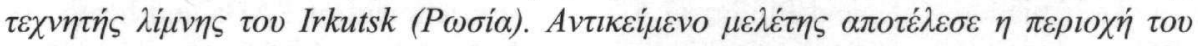

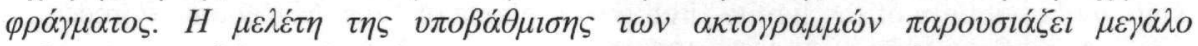

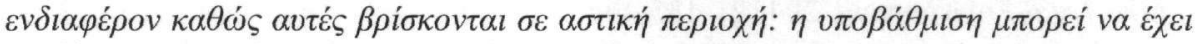

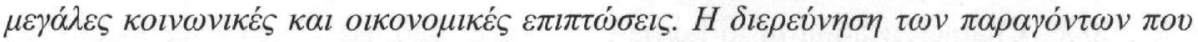

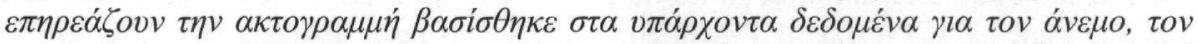

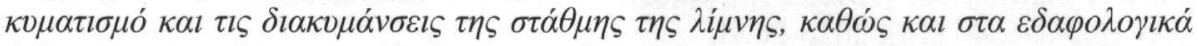

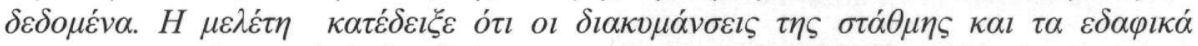

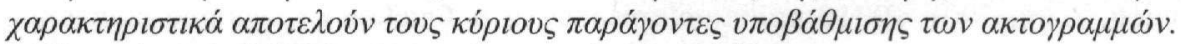

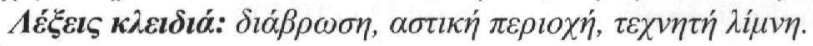

\section{Introduction}

The shore abrasion presents a rather topical problem in coastal areas in many countries (Legget 1973), being particularly hazardous in the urban territories where the shore damage can entail the disastrous consequences. The paper deals with the abrasional destruction of the coast areas within the urban territory of Irkutsk (Russia). The problem of shore abrasion arose in the "Solnechny" micro-district after the Irkutsk water-storage reservoir has been constructed.

The "Solnechny" micro-district is located in the area of river terraces near the Irkutsk reservoir's headwater. Prior to construction of the Irkutsk Hydro (which started in 1956) the geological 
environment of the territory developed in conformity with the regime of Angara-river. Since the dam construction and impounding of Irkutsk reservoir, considerable changes occurred in the hydrogeological conditions (the $35 \mathrm{~m}$ rise of water level) and the reservoir regime took the place of the river one. The changes in the geological environment entailed the development of shore abrasion in the territory.

\section{Materials and Methods}

Currently, the geological environment of the territory experiences the strong impact of the human activity. During the recent 100-year period, the vast territories of East Siberia underwent considerable economic and industrial transformation which included the development of mining industry (mines, quarries, pit heaps), building of big towns, roads and linear engineering structures and power-intensive enterprises. One of the immense engineering constructions of the region is the Angara cascade hydro-electric stations.

The construction of the Irkutsk Hydro and the water-storage reservoir started first. The building of the energy-generating plant and the rock-fill dam are located within the urban territory, which is the cause of the $35 \mathrm{~m}$ rise of water level in the area. The impounding of Irkutsk reservoir (19561962) caused the $1.2 \mathrm{~m}$ rise of Lake Baikal's water table and the $685 \mathrm{~km}^{2}$ extension of the water area.

The Irkutsk reservoir is marked by seasonal water level variations, with the 3 meters variation amplitude before 2001, and 1 meter amplitude since 2001, stated by the Russian Federation's Decree for the Lake Baikal water level regime (in the range of 456-457 m). The pattern of the yearly water level regime of the reservoir is determined as: minimum level in the period of AprilMay, gradual level rise, maximum level in September-October, and smooth lowering to the minimum.

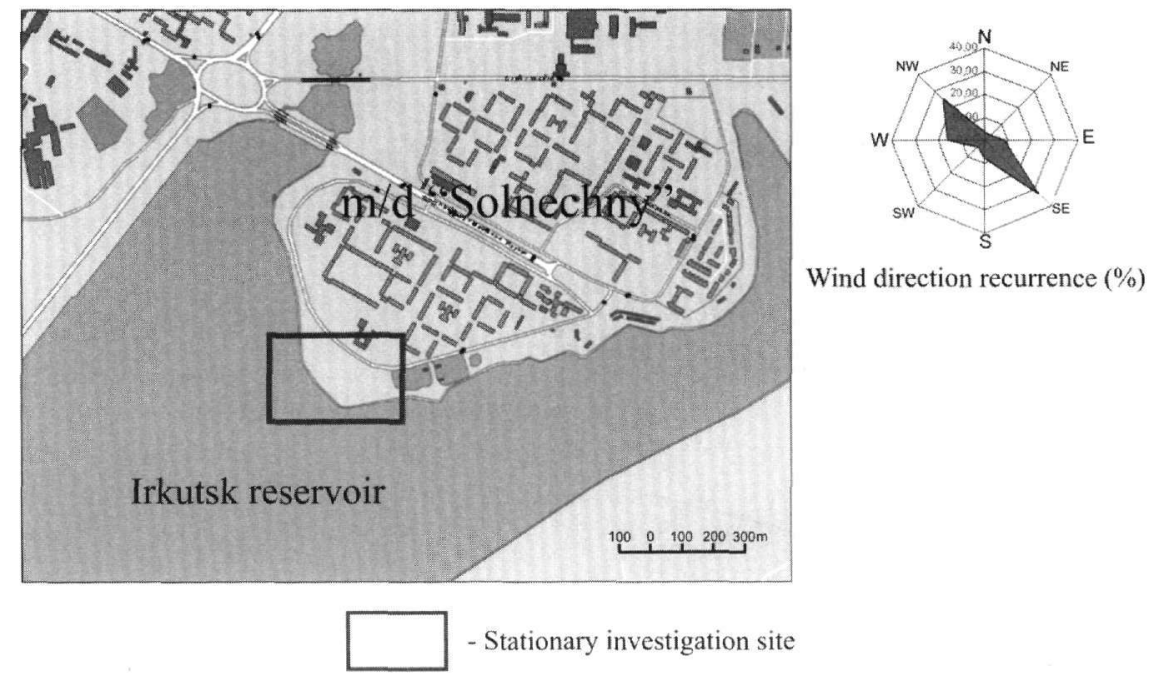

Figure 1 - Index map of the "Solnechny" micro-district

The coastal area of the Irkutsk reservoir (with the $276 \mathrm{~km}$ overall length) (Ovchinnikov et al. 2002) is marked by the intense economic and industrial development; in this territory, the settlements with garden cottages, land use for agricultural purposes, numerous recreational facilities, as well as micro-districts with buildings and facilities for public use are situated. The Irkutsk reservoir serves as the natural waterway for transportation of people, goods and materials to the Lake Baikal area. The length of abrasion-affected shores of Irkutsk reservoir is $140 \mathrm{~km}$ 
(according to G.I. Ovchinnikov's data). The dam-abutting water area is the widest and deepest part of the reservoir. The geologic-geomorphological structure of reservoir's shores is presented by the Jurassic sandrocks (left shore) and alluvial deposits such as loams, sand dust and shingle of the Angara terraces (right shore). In the Chertugey bay of the dam-abutting water area the "Raketa" pier is located which benefits to the increase of transportation rates and development of tourism in the region of Lake Baikal. Within the recent 2-3 years the coast area of the Chertugey bay was intensively built over; in spring 2004 the soil filling works and bank protection measures, as well as pier improvement were carried out. With respect to the engineering geology, all construction works neither disturbed the shore area geosystem nor induced any exogenic geological processes. However, the slopes near the protected shore areas are in hazardous state. This is the evidence of a lack of the proper strategy to control the shore conditions within the urban area.

In 2004, the stationary investigation site "Solnechny" was set up in the peninsular area of the Irkutsk-city's district of the same name (Fig. 1). Here the dynamics of shore degradation and rates of beach recession due to hollow out is studied. Since the described territory belongs to the recreation zone, its degradation can have negative social and economic consequences. The place was chosen for study for several reasons, such as: 1) easy access to the investigation site (the territory is not built over and does not belong to the areas of nature conservation; 2) the preliminary reconnaissance revealed that the area is to a large extent subject to degradation; and 3) the site is feasible for easy sample taking.

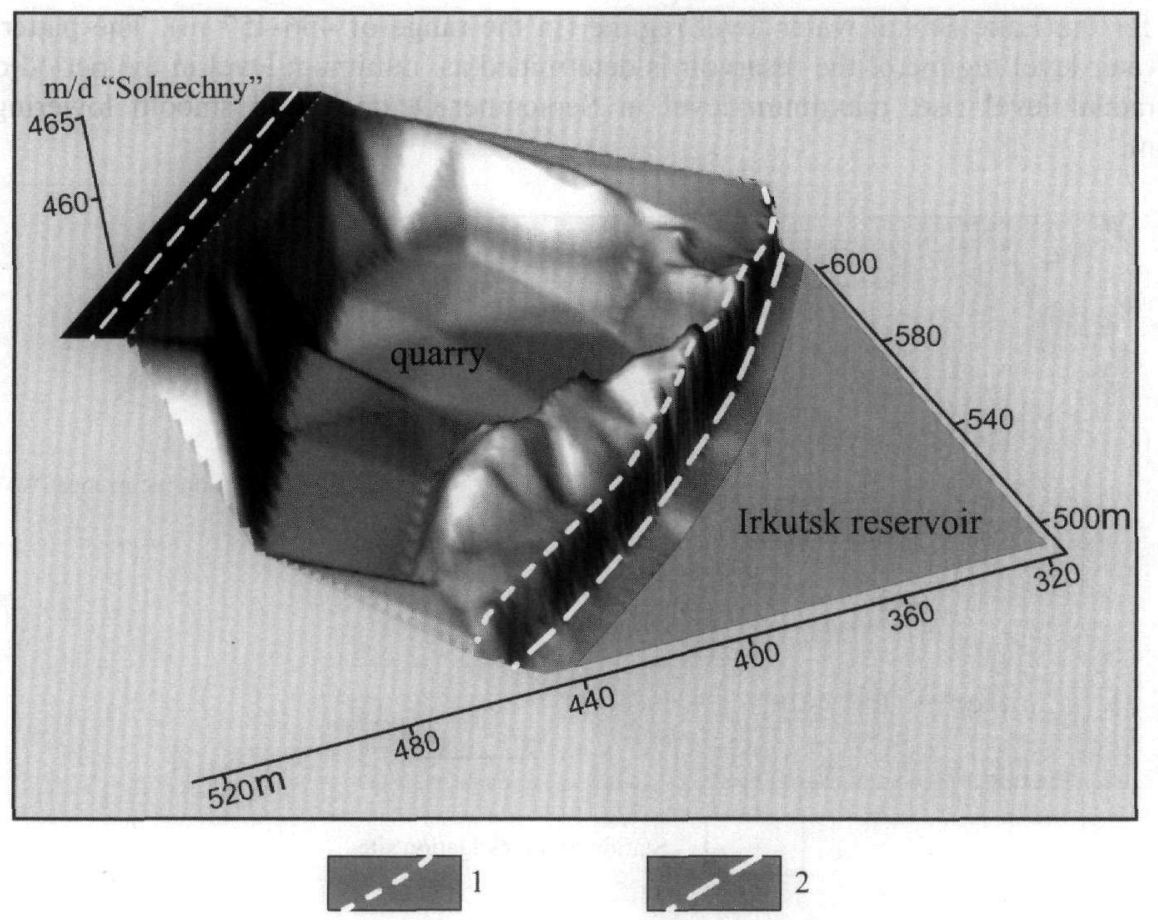

Figure 2 - Three-dimensional model of the stationary investigation site 1 - base of shore scar; 2 - shore scar brow

The methodology of site investigation includes the topographic and metric survey works, the former being designated to develop the topographic plan with the use of the closed theodolite traverse; in the course of tachometric survey the whole of the studied area can be seen. It should be noted that the tachometric survey focuses on the definite processes and relief forms; in the studied 
sites the large density of pegs is observed. The data of tachometric survey are processed in the Microsoft Excel computer program, and then the model (plan) of the studied site is constructed (Fig. 2). The model enables to estimate the spatial development of the process. By metric survey the comprehensive determination of the rates of shore line retreat can be made; for this purpose numerous landmarks are set up in the site.

In the course of investigation carried out in the "Solnechny" site, the vertical section of the quarry's wall for sampling of the ground mass was made, which shows the alternating layers of loessial loam and sand dust. The section demonstrates four layers: 1) the $0.3 \mathrm{~m}$-thick layer of vegetated soil, 2) the $0.65 \mathrm{~m}$-thick layer of brown-colored loessial sand dust, 3) the $0.65 \mathrm{~m}$-thick layer of the yellow-brown and ochreous loessial loam, and 4) the $3.2 \mathrm{~m}$-thick layer of loessial sand dust. The visible thickness of rock mass layer is $5.4 \mathrm{~m}$. The thawing depth of the ground by the time of field works (May 2004) was $0.8 \mathrm{~m}$ in the top part of the section, and $0.6 \mathrm{~m}$ in the bottom part. The grounds in the investigation site are marked by cryogenic porphyraceous and lentiform texture. The section shows the high degree of ground inundation in the base area and presence of water in the quarry's bottom.

Table 1 - Physical, phisical-chemical and deformation-enduring characteristics of grounds

\begin{tabular}{|l|l|l|l|l|l|l|l|l|}
\hline $\begin{array}{c}\text { № } \\
\text { samp. }\end{array}$ & $\mathbf{W , \%}$ & $\rho, \mathbf{g} / \mathbf{s m}^{\mathbf{3}}$ & $\begin{array}{c}\mathbf{\rho d}, \mathbf{6} \\
\mathbf{g} / \mathbf{s m}^{\mathbf{3}}\end{array}$ & $\begin{array}{c}\boldsymbol{\rho} \mathbf{s}, \\
\mathbf{g} / \mathbf{s m}^{\mathbf{3}}\end{array}$ & $\mathbf{n , \%}$ & $\mathbf{e}$ & $\begin{array}{c}\mathbf{W f}, \\
\mathbf{\%}\end{array}$ & \multicolumn{1}{|c|}{$\mathbf{S r}$} \\
\hline $4-04$ & 3,5 & 1,46 & 1,41 & 2,67 & 47,2 & 0,894 & 33,5 & 0,1 \\
\hline $5-04$ & 11 & 1,86 & 1,68 & 2,68 & 37,3 & 0,595 & 22,2 & 0,5 \\
\hline $6-04$ & 15,9 & 1,73 & 1,49 & 2,69 & 44,6 & 0,805 & 29,9 & 0,5 \\
\hline $7-04$ & 23,7 & 1,73 & 1,4 & 2,67 & 47,6 & 0,907 & 34 & 0,7 \\
\hline $8-04$ & 23,2 & 1,97 & 1,6 & 2,69 & 40,5 & 0,681 & 25,3 & 0,9 \\
\hline $9-04$ & 22,9 & 2,08 & 1,69 & 2,71 & 37,6 & 0,604 & 22,3 & 1 \\
\hline $10-04$ & 22,8 & 1,91 & 1,56 & 2,69 & 42 & 0,724 & 26,9 & 0,8 \\
\hline $11-04$ & 26,4 & 1,99 & 1,57 & 2,7 & 41,9 & 0,72 & 26,7 & 1 \\
\hline
\end{tabular}

\begin{tabular}{|l|l|l|l|l|l|l|l|l|}
\hline $\begin{array}{c}\text { № } \\
\text { samp. }\end{array}$ & $\mathbf{W}_{\mathbf{\tau}}, \mathbf{\%}$ & $\mathbf{W}_{\mathbf{p}}, \mathbf{\%}$ & \multicolumn{1}{|c|}{$\mathbf{I}_{\mathbf{p}}, \mathbf{\%}$} & $\mathbf{V}, \mathbf{s m}^{\mathbf{3}}$ & $\boldsymbol{\varepsilon}_{\mathbf{s w}} \mathbf{\%}$ & $\begin{array}{c}\mathbf{a}_{\mathbf{m a x}}(\mathbf{P}), \\
\mathbf{M p a}\end{array}$ & $\begin{array}{c}\mathbf{c}, \\
\mathbf{M p a}\end{array}$ & $\boldsymbol{\varphi}{ }^{\mathbf{o}}$ \\
\hline $4-04$ & 23,8 & 21,6 & 2,2 & 4,7 & & & & \\
\hline $5-04$ & 32,3 & 25,1 & 7,2 & 5 & & & & \\
\hline $6-04$ & 29,9 & 22,9 & 7 & 4,8 & 0,45 & $\begin{array}{c}0,34 \\
(0,2)\end{array}$ & 0,055 & 18 \\
\hline $7-04$ & 24,7 & 21,3 & 3,4 & 3,6 & & & & \\
\hline $8-04$ & 23,7 & 19,8 & 3,9 & 3,3 & & & & \\
\hline $9-04$ & 26,8 & 18,9 & 8,1 & 4,6 & & & & \\
\hline $10-04$ & 23,7 & 18,6 & 5,1 & 3,7 & & & & \\
\hline $11-04$ & 25,8 & 18,3 & 7,5 & 4,2 & & & & \\
\hline
\end{tabular}

The comprehensive analysis for estimation of the composition, structure and characteristics of loose grounds included the data of granulometric composition, with calculation of microaggregativity coefficients, physical properties (density, porosity, water saturation rate, plasticity, sedimentation volume and swelling), as well as the deformation-enduring characteristics 
(contractivity, coherence and the angle of internal friction). Besides, the structure-building components such as the water-soluble salts, carbonates, humus, sesquioxides, amorphous silicon earth and free aliminium oxides were studied (Lomtadze 1990).

By investigation the following lithoological types of ground were defined: the dark-brown and ochreous loessial sand dust of normal plasticity (plasticity number 2.2-5.1\%), different moisture contents (moisture degree 0.1-1.0) and minimum structural density (skeleton density 1.40-1.56 $\mathrm{g} / \mathrm{cm}^{3}$ ); yellow-brown and ochreous loams with maximum moisture content (1.0 water saturation rate) and maximum compaction rate (up to $1.69 \mathrm{~g} / \mathrm{cm} 3$ skeleton density). Main structure-buildung components of grounds are the argillaceous minerals, carbonates (up to $12 \%$ ), amorphous sesquioxides $(\sim 11 \%)$, water-soluble salts $(\sim 0.330 \%)$ and humus $(0.2 \%)$ (Table 1$)$.

\section{Results of investigation}

The analysis of investigation results and the available information has led to following conclusions:

The coast part with the stationary investigation site is directly abut on the main water area of the Irkutsk reservoir, experiencing therefore the essential abrasion load. Here, the domination of NW and SE winds is recorded (Table 2). The study of seas conditions in the reservoir, carried out by G.I.Ovchinnikov, revealed the wave impacts on the right shore area. In the cape part of the "Solnechny" micro-district, the average maximum for the wave height (i.e. the average wave height in the areas of maximum sea conditions) is $0.3 \mathrm{~m}$, the wave energy varying from 2.2 to 8.4 thousand tons/m (Ovchinnikov et al. 2002). In the context of geologic-geomorphological conditions, the regime of reservoir exploitation and the human influence cause the intensive degradation of this shore area.

Table 2 - Time (hours), speed (m/sec) and direction of winds during the open-water periods (May - September)

\begin{tabular}{|c|c|c|c|c|c|c|c|c|}
\hline $\begin{array}{c}\mathbf{V}, \\
\mathbf{m} / \mathbf{s e c}\end{array}$ & $\mathbf{N}$ & $\mathbf{N E}$ & $\mathbf{E}$ & $\mathbf{S E}$ & $\mathbf{S}$ & $\mathbf{S W}$ & $\mathbf{W}$ & $\mathbf{N W}$ \\
\hline $0-5$ & 364.6 & 154.1 & 154.1 & 996.4 & 755 & 395.5 & 529 & 1463.8 \\
\hline $6-10$ & 25.7 & - & - & 20.54 & 15.4 & - & 20.54 & 236.3 \\
\hline $11-15$ & - & - & - & - & - & - & - & 5.1 \\
\hline Total & 390.3 & 154.1 & 154.1 & 1016.94 & 770.4 & 395.5 & 549.54 & 1705.2 \\
\hline
\end{tabular}

The vertical section shows the pattern of distribution of the composition and state of the ground mass: the natural humidity and water saturation of grounds increase with the depth $(3.5 \%$ to $22-23$ $\%$ humidity, and 0.1 to 1.0 water saturation degree); in regard to the ground mass density three underconsolidation intervals: 1) $0.3-0.9 \mathrm{~m}$, 2) $1.6-2.0 \mathrm{~m}$, and 3) $4.5-5.0 \mathrm{~m}$ can be distinguished here. The state of grounds in the top, middle and lower areas is marked by underconsolidation and low strength characteristics $\left(0.055 \mathrm{Mpa}\right.$ coherence and the $10^{\circ}$ angle of internal friction), which induces the plastic deformation under the inundation conditions (Fig. 3).

The negatve impact on the ground characteristics is produced by seasonal freezing. The frost weathering causes the damage of structure bonds and the 2 to 4-times lowering of the strength parameters (Leshchikov and Shats 1983), which resultrs in sheeting, crumbling and sliding of the weathering products (in the form of blocks and plates) and formation of talus fans.

During the spring time (at the temperatures over $0{ }^{\circ} \mathrm{C}$ ) the thawing process and abundant water saturation of the ground lead in places to origination of the mud streams and formation of detrital cones. Owing to the high degree of water saturation, the lower layers of ground mass become 
fluid, while the upper layers lose the base, which entails the disturbance of the dynamic equilibrium and formation of fractures of $2-3 \mathrm{~cm}$ to $20 \mathrm{~cm}$ length and up to $3 \mathrm{~m}$ width parallel or subparallel to the beach scarp.

The described territory is marked by the maximum atmospheric precipitation during the summer and autumn period; the average monthly precipitation amount varies from 44 to $92 \mathrm{~mm}$ (Climate conditions..., 1981). The abundant rainfalls provoke the failure of blocks of water-saturated rock mass. At this time, the maximum retreat of the reservoir's water brink occurs. After the rainfall in June 2004, the $32 \mathrm{~cm}$ retreat of water line was recorded; during the whole observation period we recorded the $3.31 \mathrm{~m}$ retreat.

The crumbled material which accumulates at the base of beach scarp during the low water stand is washed off in the high water periods; this hampers the beach scarp flattening and formation of shoals, which could serve as the natural wave energy damper. These conditions benefit to the development of abrasion process.
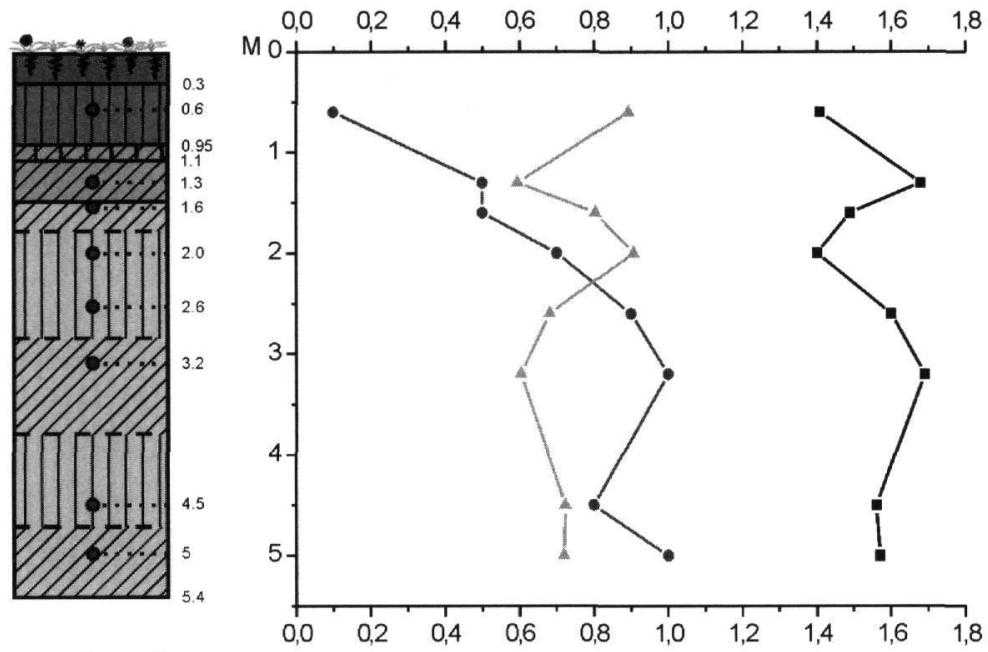

legend:
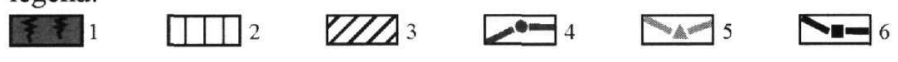

Figure 3 - Profile of the earth layer in the area of "Solnechny" district

1 - soil; 2 - clay sand; 3 - loam; 4 - water saturation degree; 5 - porosity ratio; 6 - density of soil skeleton $\left(\mathrm{g} / \mathrm{cm}^{3}\right)$

The abandoned loam quarry in the described area is also subject to the influence of exogenic geological processes. In the NE-exposed slopes the solifluction is recorded. In spring the thawed earth slips over the frozen base surface. The quarry bottom is permanently swamped, which is the cause of increased water saturation of ground. Thus, the shores of studied area experience the degradation produced by both the reservoir influence (hollow-out) and the solifluction process. The existing neck between the reservoir and quarry is of the $0.65 \mathrm{~m}$ width in the narrowest place (whereas in 2005 its width was $1.70 \mathrm{~m}$ ).

The analysis of available data shows that the essential factors influencing the shore degradation are: variations of the reservoir water level and physical, physical-chemical and deformationenduring characteristics of the ground. The level variations manifest themselves in the cyclic recurrence pattern of shore degradation process, while the ground characteristics determine the rate of its degradation. It is hardly feasible to minimize the variations of reservoir water level. The 
reservoir is marked by the seasonal level regulation, being also of the power-generating duty. The water level drawdown is determined by the economic efficiency of the power plant. The amount of generated electric power depends thus upon the practical purposes of the energy consumers. In this context, the problems of shore protection within the urban area could be solved by special measures of ground improvement.

\section{Acknowledgments}

The work has been done under financial support of RFBR (Project No. 06-05-64186)

\section{References}

Climate conditions of Irkutsk., 1981. Leningrad: Gidrometeoizdat, 245pp. (in Russian)

Legget, R.F., 1973. Cities and geology, New York: McCraw-Hill Book Company, 557pp.

Leshchikov, F.N., and Shats, M.M., 1983. Frozen rocks of the southern area of Central Siberia, Novosibirsk: Nauka. 168pp. (in Russian)

Lomtadze, V.D., 1990. The physical-mechanical characteristics of rocks. Methods of laboratory investigations, Leningrad: Nedra. 327pp. (in Russian)

Ovchinnikov, G.I., Trzhtsinsky, Yu.B., Rzetala, M., and Rzetala, M.A., 2002. Abrasiveaccumulative processes in shore zone of man-made reservoirs (on the example of southern Priangaria and Silesian Upland), University of Silesia - Faculty of Earth Sciences; Institute of Earth Crust SB RAS; Sosnowiec-Irkutsk. 102pp. (in Russian) 